G.A. Senderovich, A.V. Diachenko

\title{
A METHOD FOR DETERMINING LOCATION OF VOLTAGE FLUCTUATIONS SOURCE IN ELECTRIC GRID
}

\begin{abstract}
Purpose. The purpose of work is development of a method of definition of the location of a source of fluctuations of voltage. Methodology. The reasons of emergence of fluctuations of voltage at an arrangement of a source both in power lines, and in the consumer's networks, are connected with changes of consumption and active and reactive capacities. As criterion for definition of the location of a source of fluctuations of voltage we choose change of size of the active power received by reception substation on equivalent communication with system. The source of fluctuations of voltage is external for the consumer if emergence of fluctuations of voltage leads to the coordinated changes of tension and consumed in the area of active power that corresponds to a condition of the positive regulating effect of active loading on voltage (1). The source of fluctuations of voltage is internal for the consumer if emergence of fluctuations of voltage leads to counter changes of tension and consumed in the area of active power that resembles a condition of the negative regulating effect of active loading on voltage superficially (6). Results. The method of definition of the location of a source of fluctuations of voltage in an electric network which, works by the principle of an assessment of correlation of change of power and tension in a power supply network is developed. The method allows to consider shift between extrema of curves of change of voltage of $U(t)$ and power of $P_{\text {load }}(t)$. Originality. The method of definition of an arrangement of a source of fluctuations of voltage is developed. Practical value. The answer to this question where the source of fluctuations of voltage (in the territory of the consumer is located or in an external network) confirmed with the determined calculation, can form a basis of the expert opinion for the solution of legal disputes at an assessment of the damages caused by poor quality of electric energy. References 5 , figures 4.

Key words: quality of the electric power, indicators of quality of the electric power, fluctuation of voltage, source of fluctuation of voltage, curve of change of voltage, curve of change of active power, definition of responsibility.
\end{abstract}

Предложен метод корреляции колебаний мощности и напряжения, который позволяет определять место расположсения источника колебаний напряжения в системе электроснабжения. Библ. 5, рис. 4.

Ключевые слова: качество электроэнергии, показатели качества электроэнергии, колебания напряжения, источник колебания напряжения, кривая изменения напряжения, кривая изменения активной мощности, определения ответственности.

Introduction. In terms of defining the subjects participating in the responsibility for violation of requirements of power quality (PQ) in determining the source of voltage fluctuations (VF) in the system of power supply to consumers, with a light load, the main issue is the location of the VF source: on the territory of the consumer or in the external network. The answer to this question, confirmed by a deterministic calculation, can be the basis of expert opinion to resolve legal disputes in the assessment of damages caused by the poor quality electrical energy.

We are talking about systematic VF which are recurring in nature, and which may be at some interval measuring time $T$ to characterize by the number of voltage changes $m$, voltage repetition changes rate $F_{\delta U t}$ and other indicators relevant VF [1].

Sources of VF are powerful power-consuming equipment with a pulse, sharply changing nature of consumption of active and reactive power: arc and induction furnaces; electric welding machines; electrical motors during starting.

Problem definition. From the consumer's point of view the VF source may be placed in its electric networks or networks of other users. In the first case, if the systematic VF exceed the allowable value, the consumer must take action to reduce the level of fluctuations. In the second one - VF at consumer external factor identified as coming to him through the networks of electricity supplier. In this case, responsible for carrying out measures to reduce the level of the VF is a supplier.

The goal of the work is the development of a method for determining the location of the VF source.
The information necessary for determining the position of the VF source can be obtained by analyzing the parameters of the current mode of the power supply. As it is known, the regulatory effect of the active load voltage is almost always positive [2]

$$
\partial P_{\text {load }} / \partial U>0 .
$$

Therefore, reducing the voltage decrease caused by external factors will reduce the load active power. Accordingly, an increase in voltage caused by external factors, will lead to an increase in the load active power. With regard to reactive power, the regulatory effect of the reactive load voltage is also positive $\left(\partial Q_{\text {load }} / \partial U>0\right)$ if the voltage exceeds a critical value $\left(U>U_{c r}\right)$. With deep voltage brownouts $\left(U<U_{c r}\right)$ regulating effect of reactive load voltage becomes negative $\left(\partial Q_{\text {load }} / \partial U<0\right)$. Taking into account that for the tires $110 \mathrm{kV}$ critical voltage can reach values of the order $0.8 U_{\text {nom }}$ [2], the use of reactive power change as a criterion must be confirmed by additional research.

If the voltage change is caused by internal factors, then the object in question the voltage drop do not cause changes in other parameters of the regime, but the consequence.

Results of investigations. We represent the power supply of the consumer in the form of equivalent circuit (Fig. 1) in which $\underline{E}_{s y s t}$ is the equivalent EMF of the system; $\underline{U}$ is the voltage on the busbars of the receiving substation; $\underline{Z}_{\text {syst }}$ is the equivalent resistance of the connection with the system; $\underline{Z}_{\text {load }}$ is the equivalent resistance of the load of the enterprise.

(C) G.A. Senderovich, A.V. Diachenko 


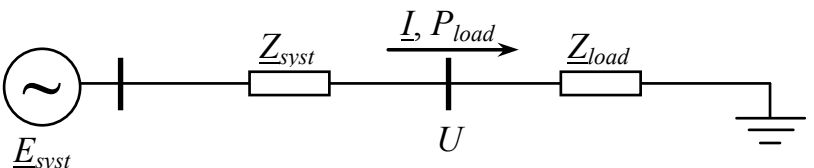

Fig. 1. Equivalent circuit of the customer power supply

Changing of the voltage $\underline{U}$ on the tires of the receiving substation caused by external to the electrical network of the consumer exposure, it can be seen as a consequence of changes in the EMF of the system $\underline{E}_{\text {syst }}$. On the assumption of the immutability of the load resistance $\left(\mathrm{Z}_{\text {load }}=\right.$ const) $E_{\text {syst }}$ reduction reduces the current $I$ on the load lines and power consumer $P_{\text {load }}$, raising $\underline{E}_{\text {syst }}-$ to increase of $I$ and $P_{\text {load }}$. In fact, when changing the voltage $U$ the load resistance $Z_{\text {load }}$ may vary somewhat, but in general, this change corresponds to a positive regulatory effect of active load by voltage $[4,5]$.

If the source of the VF is located in the electrical network of the consumer, the voltage $\underline{U}$ changes in the tires of the receiving substation is due to varying load at constant EMF of the system $\left(\underline{E}_{s y s t}=\right.$ const $)$. The voltage $U$ is determined by the loss of voltage on resistance of the connection with the system $Z_{\text {syst }}$ [5]. If we neglect the transverse component of the voltage drop, which is typical of the distribution networks, we can write:

$$
U=E_{\text {syst }}-\frac{P_{\text {load }} \cdot r_{\text {syst }}+Q_{\text {load }} \cdot x_{\text {syst }}}{U},
$$

where $P_{\text {load }}, Q_{\text {load }}$ are the powers of active and reactive consumer's load.

In accordance with (2) a prerequisite to reduce the voltage $U$ tire receiving substation at $\underline{E}_{\text {syst }}=$ const is to increase the voltage loss in the equivalent connection with the system and, hence, the numerator in the fractional part of the formula:

$$
\begin{aligned}
& \left\lfloor\left(P_{\text {load }}+\Delta P_{\text {load }}\right) \cdot r_{\text {syst }}+\left(Q_{\text {load }}+\Delta Q_{\text {load }}\right) \cdot x_{\text {syst }}\right\rfloor- \\
& -\left(P_{\text {load }} \cdot r_{\text {syst }}+Q_{\text {load }} \cdot x_{\text {syst }}\right)>0,
\end{aligned}
$$

where $\Delta P_{\text {load }}+j \Delta Q_{\text {load }}$ is the increment of power caused VF

The increase of $U$ will be observed in the case when the inequality (3) will change its sign. This is possible if the power increments will be negative $\left(\Delta P_{\text {load }}<0\right.$; $\left.\Delta Q_{\text {load }}<0\right)$.

This implies changes in the conditions of the power load, causing the VF. At a negative voltage change $\Delta U$ :

$$
\left\{\begin{array}{l}
\Delta U<0 ; \\
\Delta P_{\text {load }} \cdot r_{\text {syst }}+\Delta Q_{\text {load }} \cdot x_{\text {syst }}>0,
\end{array}\right.
$$

At a positive voltage change $\Delta U$ :

$$
\left\{\begin{array}{l}
\Delta U>0 ; \\
\Delta P_{\text {load }} \cdot r_{\text {syst }}+\Delta Q_{\text {load }} \cdot x_{\text {syst }}<0 .
\end{array}\right.
$$

Condition (5) is necessary for the emergence of the VF at the source location in the networks of the consumer, but is not sufficient. Conclusion sufficient conditions for the task is not required, since the aim is not to establish the fact of VF (VF is fixed by measurement), and the definition of the source location.

The causes of VF at the location of the source in the power network, and the network user, are associated with changes in consumption and active and reactive power. As a criterion for determining the place of supply VF location chosen change in the active power received by the receiving substation for connection with an equivalent system.

VF source is external to the consumer, if the occurrence of the VF resulting in consistent voltage changes and consumed active power line that corresponds to the condition of a positive regulator of active load voltage effect (1).

VF source is internal to the consumer, if the VF occurrence leads to changes in the counter-voltage and consumed active power line that resembles the condition of negative regulatory effect of active load by voltage:

$$
\partial P_{\text {load }} / \partial U<0 \text {. }
$$

Conditions (1) and (6) correspond to the static load characteristics and can be used in the absence of load the motor component of the consumer. In general, with the dynamic characteristics of the engines, the criteria for determining the location of the source VF requires clarification as voltage curves of the $U(t)$ and active power $P_{\text {load }}(t)$ may have a time shift $t . k_{d}$ factor which takes into account dynamic characteristics unlike the static, usually in the range $k_{d}=0.7 \div 1$ [3]. The physical meaning of the coefficient - the ratio of acceleration (or deceleration) durations $k_{d}=t_{s t} / t_{d y n}$ defined by static $\left(t_{s t}\right)$ and dynamic $\left(t_{d y n}\right)$ characteristics. At the conditions of regular VF in distribution networks when the swing changes $\delta U_{t}$ voltage is not so large to cause equipment failures, and constant inertia is much lower than on the interconnections, should expect $k_{d}$ values close to unity. At the same time, at intervals averaging close to extrema instead of criterion (1) the criterion (6) may be falsely recorded. The probability of error increases with the frequency of recurrence $F_{\delta U t}$ of voltage changes.

To take into account for a possible shift between the extremes of the curves of changes of the voltage $U(t)$ and power $P_{\text {load }}(t)$ it is advisable to make a parallel analysis of these characteristics. We consider a characteristic of change in the rms of the voltage $U$ on the consumer tires To simplify the analysis we assume that the curve $U(t)$ of voltage change is continuity of an arbitrary shape (Fig. 2).

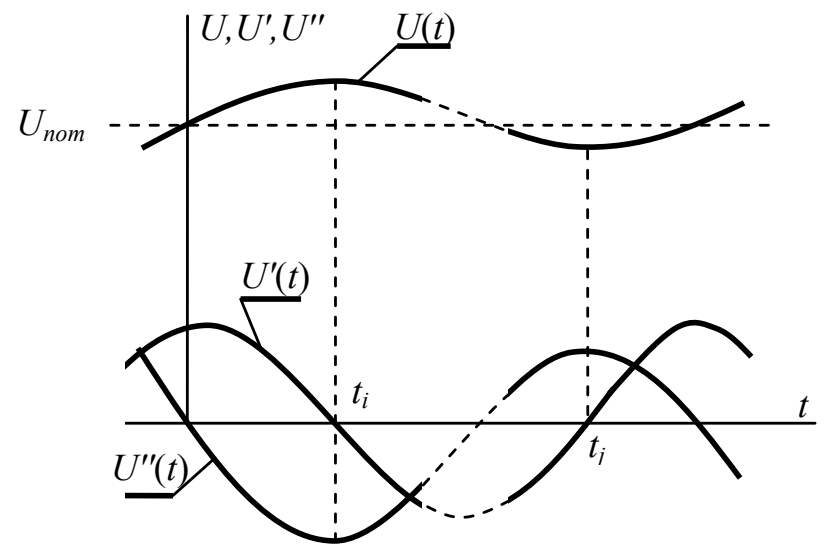

Fig. 2. Characteristics of voltage fluctuations $U(t)$, the first $U^{\prime}(t)$ and the second $U^{\prime \prime}(t)$ voltage derivatives

The smoothed shape of oscillations, in varying degrees, it is assumed in any case, as the information is received will be the integration of Instant Mode parameters for the averaging interval $\tau$. The minimum value of $\tau$ 
should be sufficient to convert the instantaneous voltage $u$ in the rms $U$ (of the order of one period of the fundamental frequency).

In the considered problem we should focus on the averaging interval $\tau$ that according to GOST [1], complies with the requirements for other indicators of quality of electric energy, which are long-lasting changes in voltage characteristics (voltage asymmetry coefficients for reverse $K_{2 U}$ and zero $K_{0 U}$ sequences ratio distortion sinusoidal voltage curve $K_{U}$ coefficient of the $n$-th harmonic component of voltage $\left.K_{U(n)}\right)$.

Whatever the curve of the voltage $U(t)$ at regular VF it is inherent in the existence of local extremes (see Fig. 2) availability of extremum conditions are known [4]. A necessary condition of the extremum of the function $U(t)$ at the point $t_{i}$ is the fact that its derivative at this point $U^{\prime}\left(t_{i}\right)$ is either zero or does not exist.

If at the point $t_{i}$ the function $U(t)$ has an extreme, and this is the maximum, then going through the $t_{i}$ point $\mathrm{f}$ the derivative changes sign from positive to negative; If at the point $t=t_{i}$ function $U(t)$ has a minimum - from minus to plus. If the derivative $U^{\prime}(t)$ when passing through the point $t_{i}$ does not change sign, the extremum at the point $t_{i}$ is absent.

To estimate the extremum sign it is possible using the second derivative. If at the point $t_{i}$ extremum is reached, and $U^{\prime \prime}\left(t_{i}\right)<0$ then the point $t=t_{i}$ the function $U(t)$ has a maximum; if $U^{\prime \prime}\left(t_{j}\right)>0$ then the point $t=t_{j}$ function $U(t)$ reaches a minimum.

Known methods of analysis of curves having local extrema can be used to estimate the power and voltage fluctuations, and in particular, to identify the source location of the VF according to the criteria (1), (6) and with the dynamic characteristics of the motor load.

We suppose that the curve of active power change $P(t)$ is similar to the voltage $U(t)$ curve and is not time shift $\left(\Delta t_{d y n}=t_{d y n}-t_{s t}=0\right)$ defined by difference of static and dynamic characteristics (Fig. 3). Then local extremum of the curve $U(t)$ will corresponds to local extrema of the curve $P(t)$. At the points of extrema $t=t_{i}, t=t_{j}$ first derivatives must be equal to zero:

$$
U^{\prime}\left(t_{i}\right)=U^{\prime}\left(t_{j}\right)=P^{\prime}\left(t_{i}\right)=P^{\prime}\left(t_{j}\right)=0 \text {. }
$$

If the source of the VF is in the system, maxima of $U(t)$ will correspond to the maxima of $P(t)$, minima - to minima (see Fig. 3,a). Signs of first derivatives $U^{\prime}(t)$ and $P^{\prime}(t)$ must be the same throughout the measurement time interval $T$ :

$$
\begin{aligned}
& \operatorname{sign} U^{\prime}\left(t_{i}\right)=\operatorname{sign} P^{\prime}\left(t_{i}\right) ; \\
& \operatorname{sign} U^{\prime}\left(t_{j}\right)=\operatorname{sign} P^{\prime}\left(t_{j}\right) .
\end{aligned}
$$

The second derivatives at the points of extrema must match the sign:

$$
\begin{aligned}
& \operatorname{sign} U^{\prime \prime}\left(t_{i}\right)=\operatorname{sign} P^{\prime \prime}\left(t_{i}\right) ; \\
& \operatorname{sign} U^{\prime \prime}\left(t_{j}\right)=\operatorname{sign} P^{\prime \prime}\left(t_{j}\right) .
\end{aligned}
$$

If the source of the VF is in the customer network, maxima of $U(t)$ will correspond to the minima of $P(t)$, minima - to maxima (see Fig. 3,b). Signs of first derivatives $U^{\prime}(t)$ and $P^{\prime}(t)$ must be opposite throughout the measurement time interval $T$ :

$$
\begin{aligned}
& \operatorname{sign} U^{\prime}\left(t_{i}\right)=-\operatorname{sign} P^{\prime}\left(t_{i}\right) ; \\
& \operatorname{sign} U^{\prime}\left(t_{j}\right)=-\operatorname{sign} P^{\prime}\left(t_{j}\right) .
\end{aligned}
$$

The second derivatives at the points of extrema must be opposite by sign:

$$
\begin{aligned}
& \operatorname{sign} U^{\prime \prime}\left(t_{i}\right)=-\operatorname{sign} P^{\prime \prime}\left(t_{i}\right) ; \\
& \operatorname{sign} U^{\prime \prime}\left(t_{j}\right)=-\operatorname{sign} P^{\prime \prime}\left(t_{j}\right) .
\end{aligned}
$$

Accounting for the dynamic characteristics of the motor load curve gives the power shift $P(t)$ with respect to the curve of voltage $U(t)$ at the time of the delay $\Delta t_{d y n}=t_{d y n}-t_{s t}$ (Fig. 4). Accordingly, local extrema of the curve $P(t)$ will be shifted relative to the extrema of the curve $P(t)$ at the time of $\Delta t_{d y n}$. For this reason, in the shear zone relations shown above (see Fig. 3) can not be observed and criteria (1), (6) will not work.

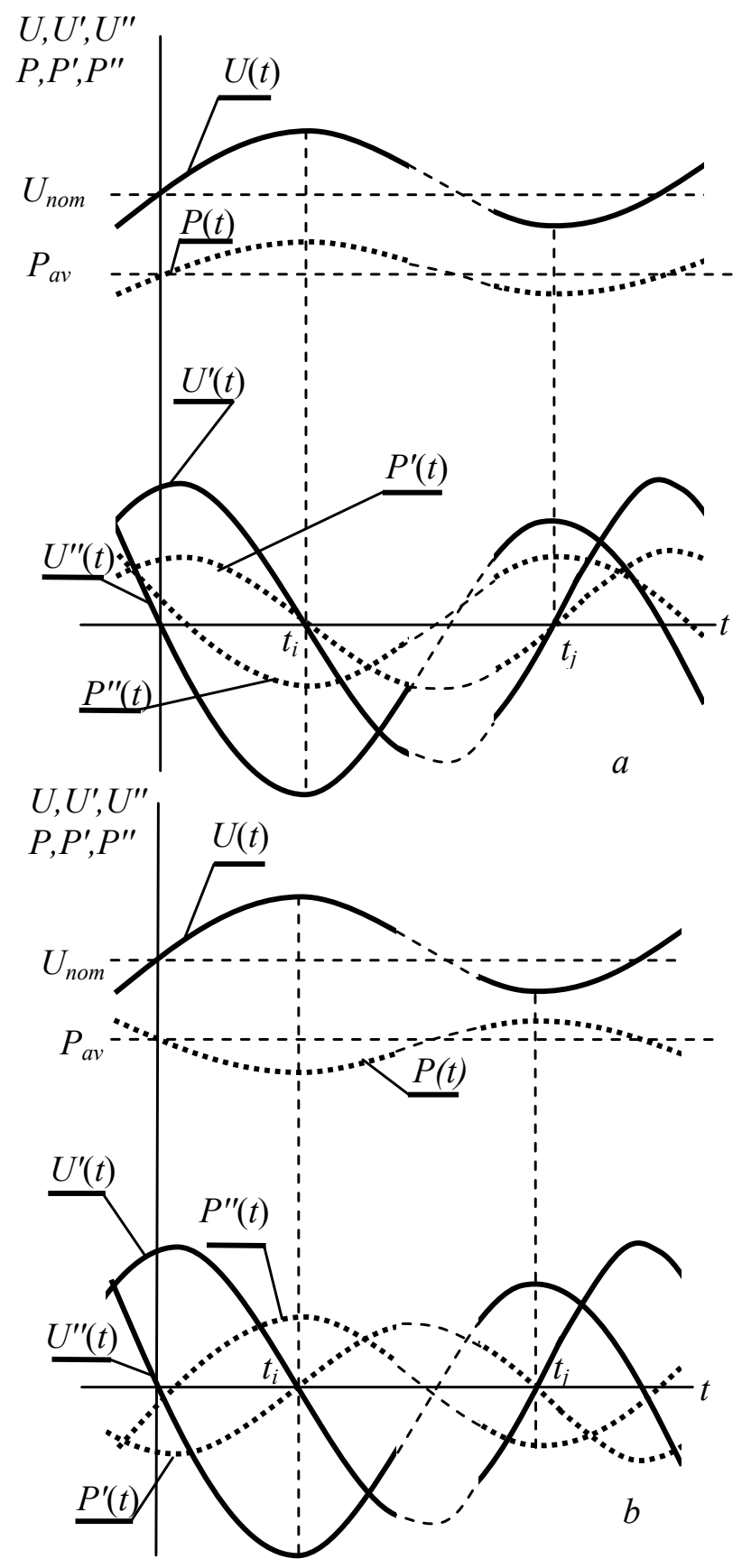

Fig. 3. Characteristics of fluctuation of voltage $U(t)$ and active power $P(t)$, their first $U^{\prime}(t), P^{\prime}(t)$ and second $U^{\prime \prime}(t)$ and $P^{\prime \prime}(t)$ derivatives at the VF source placement:

$a$-in the power supply system; $b$ - in the customer network 
It should be noted that the shift can be observed by the consumer load motor at the location of the source of $\mathrm{VF}$ in the system. If the source of VF is located in the customer network the VF are the results of changes in load power (2). The constant of the electromagnetic transient in the power line distribution network is small, the shift can be ignored.

In general case, to determine the position of the source of the VF, apparently, should be carried out parallel analysis of the curves of voltage $U(t)$ and active power $P(t)$ over the entire time interval of the measurement $T$ tracking and comparing features of their change.

In the practical analysis of information on the regime parameters coming from the registrar in the form of discrete recording of instantaneous values of current and voltage with discrete intervals, providing a given accuracy class, and, consequently, the final amount of measurements (e.g. ANTES AP-3F - 100 measurements per period). Use the information on the rms voltage and active power can be selected for the averaging interval $\tau$. Methods of determining the place of location of the VF intends to use the basic signs of change $(7) \div(11)$ of the power curve $P(t)$ with respect to the curve of voltage $U(t)$ at their the discrete implementation.

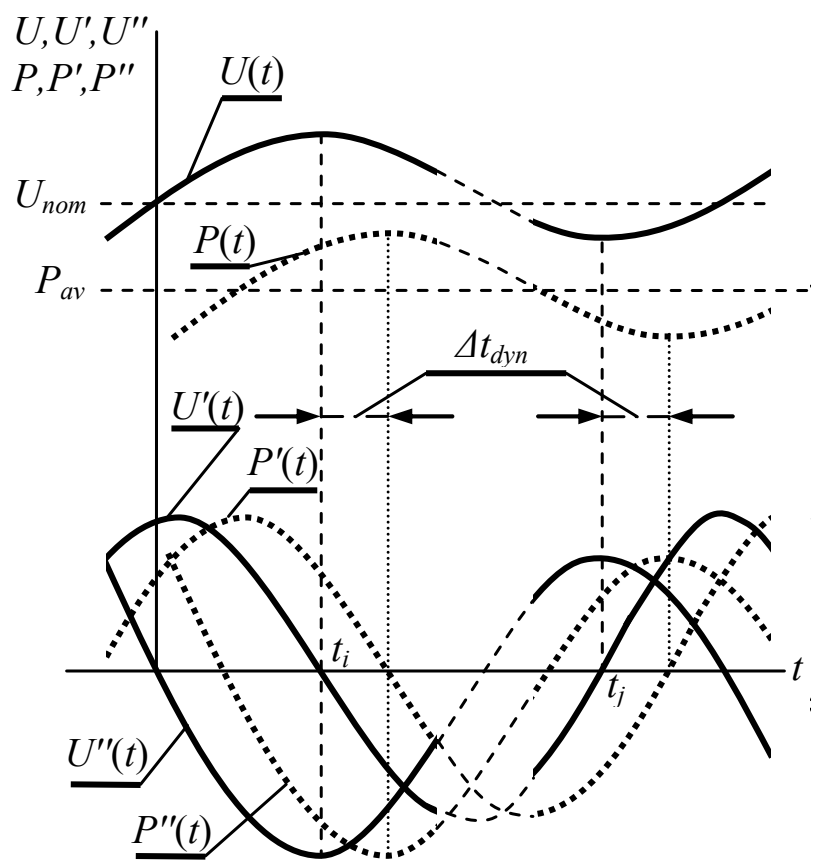

Fig. 4. Account of dynamic characteristics of the motor load

\section{Conclusions.}

1. A method for determining the location of the source of VF in the electrical network, which operates on the principle of evaluating the correlation of power and voltage changes in the power supply network is developed.

2 . The method allows to take into account the shift between the extrema of the curves of changes of the voltage $U(t)$ and power $P_{\text {load }}(t)$.

\section{REFERENCES}

1. GOST 13109-97. Elektricheskaya energiya. Sovmestimost' tehnicheskih sredstv elektromagnitnaya. Normy kachestva elektricheskoi energii $v$ sistemah elektrosnabzheniya obschego naznacheniya [State Standard 13109-97. Electrical energy. Technical equipment electromagnetic compatibility. Quality standards for electrical energy in general use power systems]. Minsk, IPK Publishing house of standards, 1998. 30 p. (Rus).

2. Idelchik V.I. Elektricheskie sistemy $i$ seti: Uchebnik dlia vuzov [Electrical Systems and Grids: Textbook for high schools]. Moscow, Energoatomisdat Publ., 1989. 592 p. (Rus).

3. Venikov V.A. Perekhodnye elektromekhanicheskie protsessy $v$ elektricheskikh sistemakh: Ucheb. dlia elektroenerget. spets. vuzov [Transitional electromechanical processes in electrical systems: Textbook for electric. specialist. high schools]. Moscow, High School Publ., 1985. 536 p. (Rus).

4. Bronshteyn I.N., Semendyayev K.A. Spravochnik po matematike dlya inzhenerov $i$ uchashchikhsya vuzov [Mathematical handbook for engineers and university students]. Moscow, Nauka Publ., 1986. 723 p. (Rus).

5. Senderovich G.A., Diachenko A.V. The relevance of determining responsibility for violation of power quality in terms of voltage fluctuations. Elektrotekhnika i elektromekhanika - Electrical engineering \& electromechanics, 2016, no.2, pp. 54-60. (Rus). doi: 10.20998/2074-272X.2016.2.10.

G.A. Senderovich ${ }^{1}$, Doctor of Technical Science, Professor, A.V. Diachenko ${ }^{1}$, Postgraduate Student,

${ }^{1}$ National Technical University «Kharkiv Polytechnic Institute», 21, Frunze Str., Kharkiv, 61002, Ukraine, phone +380952098150 ,

e-mail: senderovichg@mail.ru, alex.7491@mail.ru

How to cite this article:

Senderovich G.A., Diachenko A.V. A method for determining location of voltage fluctuations source in electric grid. Electrical engineering \& electromechanics, 2016, no.3, pp. 58-61. doi: 10.20998/2074-272X.2016.3.09. 